\title{
Editorial:
}

\section{Targeting Services to Older Adults at Risk: A Balancing Act}

As people become older, remaining in the community often implies taking more risks. According to Ruth Raymond Thone (1992), "One of the wonders of risking is that it is a sure path to personal power, not power over another but power within one's self. Risk taking is confidence-building, the results of which hang in with you no matter what happens."

Important questions arise as older adults become increasingly frail and potential risks in staying in their homes become greater. Is the health and social service system able to meet their needs by offering the necessary support and do professionals explain the risks implied in their different lifestyles and care packages?

Canadians are living longer and while some are enjoying their "so-called" golden years, for others aging may be a source of worry and anxiety. Even though Canada has a relatively young population compared with most industrial societies, Canadians who are aged $80+$ are increasing in number even more rapidly than those in the bulk of Western countries. These trends have enormous implications for older people themselves as well as for provincial long-term care strategies and programs. Their impact can be seen in the long-term care health and social services reforms presently sweeping most of the Canadian provinces. At the heart of all the reforms is a trend toward community-based care, more individualized and personalized care packages, decentralization of services, with co-ordinated and integrated organizational long-term care plans. Accessibility and availability of services to individuals and their families is stressed as well as emphasis on paying attention to people's cultural needs and backgrounds.

In this issue of the Journal, Young, Forbes and Hirdes present a study which reviews the association of disability with long-term care institutionalization of the elderly. The data analysed from the Health and Activity Limitation Survey (HALS) indicate that persons with disabilities, namely agility, mental functioning or speech, have higher odds of institutionalization. This may imply that a decrease in such disabilities through rehabilitation programs, for example, may lead to a decrease in the possibility of their institutionalization. The authors further suggest that help could be provided through assistive devices and that targeting services to those elderly people at greater risk for institutionalization may be of value. It should be noted that in the United States in the 1990s the most striking feature in care for the elderly has been a shift from patient-centred to devicebased care (Nahmiash and Reis, 1992). However, this same shift toward use of technology has sparked a simultaneous counter-revolution toward 
"hands-on" care. Paying attention to the emotional needs of patients and the possibility of increased isolation of the elderly from expanding use of technology has been noted. A balance may be what is needed in providing assistance through technological devices and increased social support though human resources.

Young and Forbes also point out that the HALS Survey notes the physical risk factors for those elderly persons to be targeted to the institutional sector but does not take into account other factors which may also be helpful in producing a risk profile of older adults. A recent study sponsored by Health and Welfare Canada (1993) highlights a number of factors influencing institutionalization, such as the effects of socio-economic status and education, which may enable older women to accumulate means so that they may not have to depend on the state for their institutional care costs. A Quebec Ministry study (Ministère de la Santé et des Services Sociaux, 1991) identifies from the literature factors associated with long-term care placement: advanced age; living alone; the presence of functional and mental disabilities; a recent hospitalization.

However, the same study points out the importance of environmental and social factors, such as availability of home care supports and services, a diversity of professional practises, loss of a spouse and even factors such as the steps a person may have to take in requesting long-term care resources. The Manitoba Health Care Studies (Manitoba Centre for Health Policy and Evaluation, 1991) similarly suggest the use of risk profiles for government planning and the need to identify those persons who might benefit from special attention. In these studies the third greatest risk factor for admission to Personal Care Homes (PCHs) is an inability to meet day to day needs (cooking, housekeeping, etc.) and they suggest that for the very elderly receiving home care, for reasons other than life threatening illness, is a substitute for $\mathrm{PCH}$ care. Another interesting finding from these studies is that the older the person is, the more he or she is likely to have been admitted from the community, as opposed to from a hospital or PCH and that elderly persons who rate their health as poor die sooner than those who think their health is good, even though their objective health status is similar. This finding suggests that those who rate their health as poor could also be regarded as being at higher risk than those who do not. It is important to have risk profiles which take into account all of these factors.

The Report of the British Columbia Royal Commission on Health Care and Costs (1991) highlights the fact that care provided in the home or on an out-patient basis is preferable to institutionalization. However, the report points out that "whether home care is viable depends largely on the resources that support it and the government must be prepared to commit a realistic portion of its funding to care in the community". This statement is of extreme importance and may be critical in the success of long-term care reforms in the future, since providing adequate community supports to those living alone or to caregivers, who are already providing 70 to 80 per cent of the care for the elderly, will mean a reallocation of resources in some 
provinces as well as an ability to target those who are at risk and in need of long-term care services. On the other hand, we must not only target those who are severely disabled for services. It is also important to provide preventive programs for the reduction of falls, preventive counselling services for those suffering from the loss of a spouse and community-based services and supports to meet the needs of those frail older adults who wish to stay in their homes. A recognition of the contribution and importance of home and community support services, which enhance community-based care through providing meals, visits, transportation, etc., may also be influential in preventing premature institutionalization. The Ministry of Community and Social Services Ontario (1990) stresses the importance of building "a coherent integrated service system" with emphasis on co-ordinating access to services and information and building an enhanced system of community support services. Young, Forbes and Hirdes recommend that decreasing severe disabilities of older adults will decrease the need for institutionalization.

It remains to be seen whether the current reform plans will be effective in targeting older adults at risk for institutionalization. To what extent will the use of appropriate risk profiles, reallocation of adequate resources to community-based care and the building of a strong community-based service system with home supports and support for informal caregivers meet the future needs of increasing numbers of older adults? In the past, gerontologists and planners have encouraged home care programs to give priority to those people whose functioning is severely impaired. However, more and more family caregivers (mainly women) are becoming burdened or "burntout" through caring for severely impaired adults with too few supports and for too long a time. Hopefully, planners and providers will find the balance between targeting the severely disabled and supporting family caregivers at risk in a way which does not place too much of the burden for care on women.

Finally, older adults have expressed a wish to remain in their homes and communities for as long as possible. In a large recent survey in Quebec (Fédération des CLSC du Québec, 1991) 93 per cent of seniors said they wished to stay in their homes. This implies for older adults, with multiple disabilities, a number of risks and responsibilities. It is therefore important as we offer services and choices to older adults that we also clarify the risks and responsibilities which the alternative options entail for the older person. In this way the elderly persons or their family members may make informed choices about their lifestyles, what is available to them and the risks they wish to make.

\section{References}

British Columbia Report. (1991). Royal Commission on Health Care and Costs. Victoria: Crown Pubications Inc.

Fédération des CLSC du Québec. (1991). Viure chez soi. Actes du forum sur le soutien à domicile. Montréal. 
Health and Welfare Canada. (1993). Vieillissement et institutionnalisation: Impact de l'évolution des caractéristiques socio-démographiques des personnes âgées (No. 4, 577-14-9R. Ottawa).

Manitoba Centre for Health Policy and Evaluation. (1991). Manitoba Health Care Studies and Their Policy Implications. Winnipeg: Government of Manitoba.

Ministère de la Santé et des Services sociaux. (1991). Les facteurs associés à l'orientation des personnes âgées dans des établissements d'hébergement: Une revue de la littérature. MSSS Planification-Évaluation, Santé et Services sociaux, Québec.

Ministry of Community and Social Services. (1990). Strategies for change. Comprehensive Reform of Ontario's Long-term Care Services. Toronto: Queen's Printer for Ontario.

Nahmiash, D., \& Reis, M. (1992). An exploratory study of private home care services in Canada. Community Health Division. Ottawa: Health and Welfare Canada, Minister of Supply and Services Canada.

Daphne Nahmiash 